\title{
VAISTINIU巳 AUGALŲ PASIRINKIMAS ACNE VULGARIS GYDYMUI IR PREVENCIJAI
}

\author{
Mindaugas Rutalè $\dot{e}^{1}$ Jurgita Daukšienè $\dot{e}^{1,2}$, Ona Ragažinskiene் $\dot{e}^{2,3}$ \\ ${ }^{1}$ Lietuvos sveikatos moksly universiteto Farmacijos fakultetas, ${ }^{2}$ Kauno kolegijos \\ Medicinos fakultetas, ${ }^{3}$ Vytauto Didžiojo universiteto Botanikos sodas
}

Raktažodžiai: tradicinès papildomos medicinos priemonès, vaistiniai augalai, paprastieji spuogai.

\begin{abstract}
Santrauka
Vaistingieji augalai yra biologiškai aktyvių junginių šaltinis. Jie plačiai taikomi lètinių ir ūmių ligų terapijai. Viena iš galimų terapijos sričių yra dermatologija. Dermatologijos srityje augalų sintetinami biologiškai aktyvūs junginiai naudojami kaip sisteminio ir vietinio poveikio priemonès. Tokia jų pritaikymo galimybė puikiai tinka kovojant su paprastujų spuogu (aknès) atsiradimu.

Tyrimo tikslas - ịvertinti vaistinių augalų naudojimą tarp paprastaisiais spuogais sergančių pacientų. Tyrimas atliktas Vilniaus ir kitu Lietuvos miestu visuomenès vaistinèse. Tyrimas apèmè 500 respondentų, atsakomumas 80,6 proc. Tiriamieji buvo suskirstyti i dvi grupes: naudojančius vaistinguosius augalus $(\mathrm{N}=246)$ ir nenaudojančius vaistingujjų augalų $(\mathrm{N}=157)$. Gauti duomenys palyginti tarpusavyje nustatant statistiškai reikšmingą skirtumą tarp respondentų bei z kriterijų. Tyrimo rezultatai - visuomenès vaistinès pacientai aktyviai naudoja vaistinguosius augalus kaip papildomą tradicinę medicinos priemonę aknès gydymui ir prevencijai ( $65 \%$ ). Statistiškai reikšmingo skirtumo tarp vaistinguosius augalus naudojančių ir nenaudojančių respondentų tyrime nerasta. Vaistinguosius augalus dažniau renkasi respondentai, susiduriantys su paprastaisiais spuogais ilgiau negu 10 metų $(\mathrm{p}<0,05)$. Išvados: vaistingieji augalai yra potencialiai tinkamas terapijos būdas pacientams, kuriuos kamuoja lètinè paprastujų spuogų būklè. Vaistingieji augalai gali būti naudojami kaip papildomas terapijos įrankis esant ūmiai paprastųjų spuogų būklei.
\end{abstract}

\section{Ivadas}

Paprastieji spuogai (Acne vulgaris) - lètinè uždegiminè liga, kuri, remiantis atliktais tyrimais, yra trečia dažniausiai pasitaikanti dermatologinè liga 12-25 metų amžiaus asme- nims [1] bei aštunta tarp visų dažniausiai paplitusių lėtinių ligų [2]. Paprastieji spuogai išsivysto dèl suaktyvejjusios lytinių hormonų veiklos brendimo laikotarpiu, Propionibacterium acnes, ir Staphylococcus epidermidis opurtunistinès infekcijos, hiperkeratinizacijos bei sebocitu proliferacijos sutrikimu [3]. A. vulgaris gydymui naudojami ne tik receptiniai vaistai, pavyzdžiui, sisteminio ir vietinio veikimo antibiotikai, retinoidai, benzoilo peroksidas, azelaino rūgštis ir adapalenas, bet ir vaistingieji augalai $[4,5]$.

Aknès gydymui ir profilaktikai naudojami augalai, kurie kaupia eterinius aliejus, flavanoidus, riebiąsias rūgštis bei antioksidantus. Eteriniai aliejai pasižymi stipriu antibakteriniu poveikiu - stabdo P.acnes ir S.epidermidis augimą ir vystymąsi, todèl sumažèja liaukų uždegimas. Šiuo poveikiu pasižymi terpinen-4-olis, cineolis, 1,8-cineolis, linalolis, eugenolis, timolis ir kt. Šiuos eterinius aliejus labiausiai kaupia Myrtaceae šeimos augalai - pražangialapè mirtenè (Melaleuca alternifolia L.) ir įvairių rūšių eukaliptai (Eucalyptus spp.) [5]. Flavanoidų, ypač hesperidino, kvercitino, apigenino, priešuždegiminis poveikis pasireiškia gebejjimu inhibuoti fermentus, aktyvuojančius prostaglandinus, leukotrienus, citokinus, chemokinus. Dèl to sumažèja paraudimas, pūslelių, pustulių susidarymas bei skausmas [6]. Biologiškai aktyvius flavanoidus labiausiai kaupia Asteraceae (Compositae) šeimos augalai - vaistinè medetka (Calendula officinalis L.), vaistinè ramunè (Chamomilla recutita $\mathrm{L}$. Rauschert.), kalninè arnika (Arnica montana L.) [5]. Dygliuotasis šaltalankis (Elaeagnaceae), literatūroje geriau žinomas kaip Hippophae rhamnoides, vaisiuose ir sẻklose kaupia nesočiąsias riebalų rūgštis (steario, linoleno, oleino, palmitino), karotinoidus ( $\beta$-karoteną), $\alpha$-, $\beta$-, $\gamma$-tokoferolius, sterolius (stigmasteroli, $\beta$-sitosteroli, kampesterolị). Minèti junginiai skatina žaizdų gijimą, audinių regeneraciją, mažina audinių oksidacinị stresą [7].

Tyrimo tikslas - įvertinti vaistinių augalų naudojimą gydymui ir profilaktikai tarp visuomenès vaistinès pacientu, susiduriančių su acne vulgaris. 
1 lentelè. Sociodemografiniai vaistinius augalus naudojančių respondentų duomenys

\begin{tabular}{|c|c|}
\hline Demografinis kriterijus & $\mathbf{N}(\%)$ \\
\hline \multicolumn{2}{|l|}{ Amžius } \\
\hline$<18$ & $76(18,9)$ \\
\hline $18-29$ & $262(65)$ \\
\hline $30-49$ & $61(15,1)$ \\
\hline$>50$ & $4(1)$ \\
\hline \multicolumn{2}{|l|}{ Lytis } \\
\hline Moteris & $297(73,7)$ \\
\hline Vyras & $106(26,3)$ \\
\hline \multicolumn{2}{|l|}{ Išsilavinimas } \\
\hline Vidurinis ar žemesnis & $221(54,9)$ \\
\hline Universitetas & $110(27,3)$ \\
\hline Kolegija & $72(17,8)$ \\
\hline \multicolumn{2}{|l|}{ Šeimyninė padėtis } \\
\hline Vedęs/ištekèjusi & $210(51,1)$ \\
\hline Vienišas/Vieniša & $193(47,9)$ \\
\hline \multicolumn{2}{|l|}{ Aknès trukmė } \\
\hline$<10$ metų & $249(61,8)$ \\
\hline$>10$ metų & $154(38,2)$ \\
\hline \multicolumn{2}{|l|}{ Aknės būklès sunkumas } \\
\hline Lengva/vidutinè & $358(89)$ \\
\hline Sunki & $45(11)$ \\
\hline
\end{tabular}

\section{Tyrimo objektas ir metodika}

Tyrimas atliktas Vilniaus ir kitų Lietuvos miestų visuomenès vaistinèse. Tyrimo įrankis - specialiai parengtas klausimynas. Anketą sudare klausimai apie respondentų demografinius duomenis (lytis, amžius, išsilavinimas), patirtị sergant akne (sunkumas, trukmè) bei vaistinių augalų naudojimas. Tyrime dalyvavo asmenys, kurie vaistinejje kreipèsi dėl paprastujų spuogu gydymo ir profilaktikos. Tyrimo metu išdalinta 500 anketų, atsakymus pateikè 403 , atsakomumas $80,6 \%$. Surinkti duomenys apdoroti naudojant IBM SPSS (Statistical Package for Social Science) 17.0 programinès statistinès analizès versiją bei MS Excel 2013. Rezultatai laikyti statistiškai reikšmingais, kai patikimumo koeficientas $p<0,05$.

\section{Tyrimo rezultatai}

Tiriamujų asmenų amžiaus vidurkis 24,05 metai $\pm 1,45$ metų, (amžiaus ribos 14-65). Tyrime dalyvavo 73,7 \% moterų, didžioji dalis respondentų $-54,9 \%$ turèjo vidurini ar žemesnį išsilavinimą. Apie $51 \%$ respondentų gyveno su partneriu (-e). Dauguma respondentų, paprašyti apibūdinti esamą aknès būklę, apibūdino kaip lengvą arba vidutinio vencijai
Pinus sylvestris I

Cinnamomum ceylanicum $L$

ucalyptus globulus Labill.

Origanum vulgare Linn.

Thymus vulgaris $L$.

Melaleuca artenifolia L

Calendula officinalis $L$

Hippophae rhamnoides $L$.

Persea americana L

Chamomilla recutita(L.) Rauschert

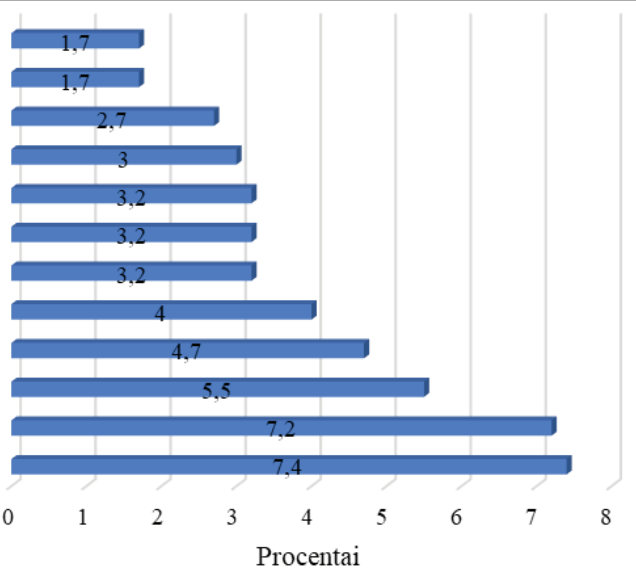

1 pav. Vaistiniai augalai naudojami per os sistemiškai acne vulgaris gydymui ir pre-

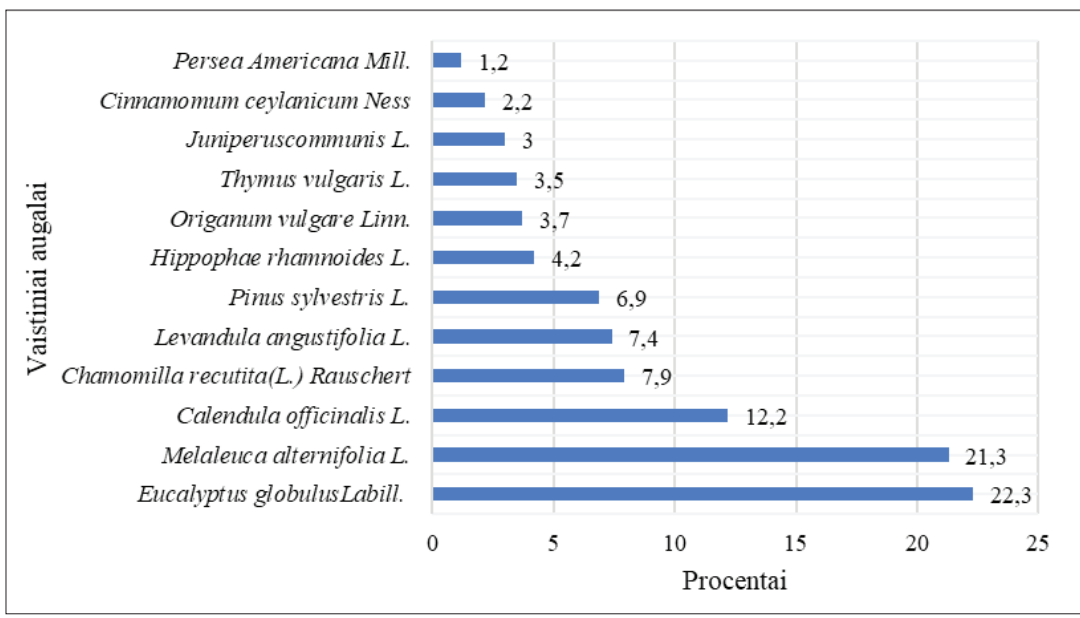

2 pav. Vietiškai naudojami vaistiniai augalai acne vulgaris gydymui ir profilaktikai

sunkumo (89\%) ir nurodè, kad jų patirtis gydant aknę yra trumpesnè negu 10 metų $(61,8 \%)$. Tyrimo respondentų demografiniai duomenys pateikti 1 lentelèje.

Atlikus tyrimą pastebeta, kad statistiškai reikšmingo skirtumo tarp vaistinius augalus naudojančių ir jų nenaudojančių respondentų nėra. Lyginant amžiaus grupes, pastebėta, jog vaistinius augalus naudoti labiau yra linkę jaunesni negu 30 metų asmenys $-62,01 \%$. Taip pat pastebėta, jog dažniau vaistiniai augalai patraukia vyrų dèmèsị - 63,2\% lyginant su moterimis $-60,26 \%$, tačiau, kaip minèta pradžioje, statistiškai reikšmingo skirtumo nerasta $-p>0,05$. Aukštasis išsilavinimas $-56,59 \%$ irgi nesuteikia pranašumo rinktis vaistinguosius augalus kaip galimą terapijos sritį lyginant su asmenimis, kurie turi vidurinị ar žemesnị išsilavinimą $\mathrm{p}>0,09692$. Respondentai, kurie atsakè gyveną vieni, kiek dažniau naudoja vaistinius augalus lyginant su responden- 
tais, gyvenančiais santuokoje ar su partneriais $(63,73 \%$ ir $58,57 \%, \mathrm{p}>0,05)$. Statistiškai reikšmingas skirtumas rastas tarp aknès būklès trukmès ir vaistinių augalų naudojimo - sergant ilgiau negu 10 metų, dažniau renkamasi naudoti augalus ir priešingai $(\mathrm{p}<0,05)$. Tai galima susieti su aknès būkle - patiriant ilgai paprastųjų spuogų simptomus, kurie labiausiai reiškiasi paauglysteje, išbandomos visos įmanomos ir pasiekiamos priemonès $-64,44 \%$ respondentų renkasi augalus lyginant su 60,61 \% atsisakančiais juos naudoti.

Kaip ir minèta pradžioje, acne vulgaris patologijos gydymui ir profilaktikai tinkamos priemonès naudojamos sistemiškai per os ir vietiškai ant odos. Sisteminiam (1 pav.) naudojimui augalai pasirinkti kur kas rečiau nei vietiniam (2 pav.). Dažniausiai naudoti sisteminiam poveikiui - vaistiné medetka, amerikiné persèja bei digliuotasis šaltalankis. Rečiausiai pasirinktas paprastasis kadagys, paprastoji levanda bei paprastoji pušis.

Vietiniam naudojimui respondentai dažniausiai renkasi apskritalapio eukalipto, arbatmedžio eterinị aliejų - daugiau negu penktadalis respondentų taiko šiuos augalus. Kiek rečiau vietiškai, bet dažniau nei sistemiškai naudojama vaistinè medetka ir vaistinè ramunè (2 pav.).

\section{Aptarimas}

Vaistinių augalų paprastujų spuogų gydymui naudojimas populiareja dẻl keleto svarbių priežasčių: slopina patogeninių mikroorganizmų augimą ir vystymąsi - tai labai svarbi visuomenès sveikatos problema, nes daugèja antibiotikams atsparių mikroorganizmų padermių ir štamų, taip pat slopina uždegimo mediatorių išsiskyrimą iš putliųjų ląstelių bei saugesni [5].

Mokslininkų ir tyrejjų studijos iliustruoja vis labiau populiarejjančių vaistinių augalų naudojimo dažnumą, jų teigiamą sinergetinį poveikị naudojant keletą terapijos rūšių - vaistinius augalus su receptiniais ir nereceptiniais vaistais. Norimam efektui pasiekti pasirenkami skirtingi vaistinių augalų naudojimo būdai - arbatos, ekstraktai, tepalai, kremai bei losjonai $[5,8]$.

Vienas iš galimų sèkmès pavyzdžių 2015 metais pateikta K.A. Hammer studija apie pražangialapès mirtenès (Maleleuca artenifolia L.) taikymą aknès gydymui ir profilaktikai. Šis medicinoje platų pritaikymo spektrą turintis augalas savo eterinio aliejaus sudettyje kaupia apie 100 skirtingos struktūros junginių, tačiau biologini aktyvumą prieš aknès patogenines bakterijas suteikia terpinen-4-olis - tai pagrindinè jo sudedamoji dalis (40 $\%$ viso eterinio aliejaus). Jo efektyvus poveikis lyginant su placebo pastebètas naudojant du kartus per parą 6 savaites, lyginant jo efektyvų poveikị su $2 \%$ eritromicino geliu, $5 \%$ mirtenès gelis statistiškai veiksmingesnis abu preparatus naudojant ir du katus per parą 6 savaites [9].

\section{Išvados}

1. Visuomenès vaistinès klientai, susiduriantys su acne vulgaris simptomais, jų gydymui ir prevencijai naudoja vaistinius augalus.

2. Dažniausiai pasirenkamas vietinis vaistinių augalų naudojimo būdas.

3. Remiantis literatūros ir tyrimo duomenimis, kaip vieną iš galimų gydymo ir prevencijos nereceptinių priemonių, pasirenkami pražangialapès mirtenès produktai - praskiestas eterinis aliejus arba kosmetinès priemonès, savo sudètyje turinčios minètą eterinį aliejų.

\section{Literatūra}

1. Lynn DD, Umari T, Dunnick CA, Dellavalle RP. The epidemiology of acne vulgaris in late adolescence. Adolescent health, medicine and therapeutics, 2016; 7: 13-25.

https://doi.org/10.2147/AHMT.S55832

2. Tan JKL, Bhate K. A global perspective on the epidemiology of acne. British Journal of Dermatology 2015; 172(1):3-12. https://doi.org/10.1111/bjd.13462

3. Dreno B, Martin R, Moyal D, Henley JB, Khammari A, Seité S. Skin microbiome and acne vulgaris: Staphylococcus, a new actor in acne. Experimental dermatology, 2017;00:1-6.

4. Vera N, Patel N, Cardwell LA, Saleem M, \& Feldman SR. Chemical pharmacotherapy options for managing adult acne. Expert opinion on pharmacotherapy, 2017; 18(3): 263-273. https://doi.org/10.1080/14656566.2017.1282460

5. Nasri H, Bahmani M, Shahinfard N, Nafchi AM, Saberianpour S, Kopaei MR. Medicinal plants for the treatment of acne vulgaris: a review of recent evidences. Jundishapur Journal of Microbiology 2015; 8(11):25580

https://doi.org/10.5812/jjm.25580

6. Kumar S, Pandey AK. Chemistry and biological activities of flavonoids: an overview. The Scientific World Journal 2013. https://doi.org/10.1155/2013/162750

7. Kapoor DN. A review on pharmacognostic, phytochemical and pharmacological data of various species of Hippophae (Sea buckthorn). International Journal of Green Pharmacy 2017; 11(01):62-75.

8. Sinha P, Srivastava S, Mishra N, Yadav NP. New perspectives on antiacne plant drugs: contribution to modern therapeutics. BioMed research international, 2014.

https://doi.org/10.1155/2014/301304

9. Hammer KA. Treatment of acne with tea tree oil (melaleuca) products: a review of efficacy, tolerability and potential modes of action. International Journal of Antimicrobial Agents 2015; 45(2):106-110.

https://doi.org/10.1016/j.ijantimicag.2014.10.011 


\section{MEDICINAL PLANTS CHOISES FOR ACNE VULGARIS TREATMENT AND PREVENTION \\ M. Rutalè, J. Daukšienė, O. Ragažinskienė}

Key words: acne vulgaris, medicinal plants, complementary medicines therapies.

Summary

Acne vulgaris - one of most common skin and chronic disease. One of possible treatment and prevention measure - botanical drugs. These drugs can be using single or botht with prescriptions and/or non-prescription drugs. The main aim of our study was to find out what herbal medicines are using for acne vulgaris treatment and prevention among community pharmacy patients.

Methods and results: The method was a cross-sectional questionnaire. Five hundred questionnaires were distributed at community pharmacies in Vilnius and others Lithuania cities. The response rate was $80,6 \%(\mathrm{~N}=403)$. Statistical significant differences among herbal medicine users and non-users weren't found, except among acne vulgaris duaration: patients suffering more than 10 years, more often use medicinal plants. For topically use most often was chosen Eucalyptus globulus Labill. (22,3 \%). For systematically use most often was chosen Chamomilla recutita (L.) Rauscher.(7,4 \%)

Conclusions: medicinal plants are using for acne vulgaris treatment and prevention among community pharmacy patients in Lithuania.

Correspondence to: jurgita.dauksiene@gmail.com

Gauta 2017-10-27 